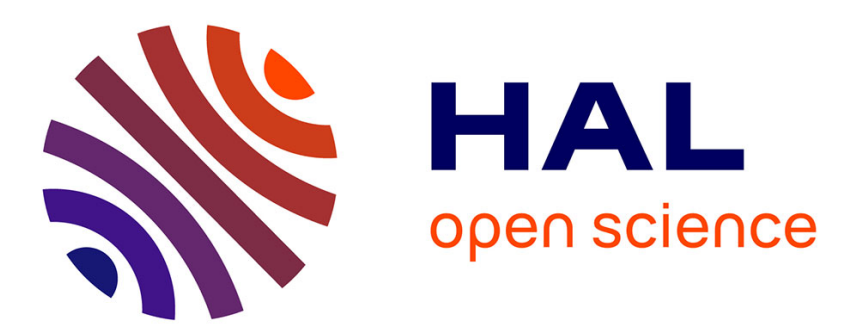

\title{
Effects of a non-adsorbing polymer on colloid stability: force measurements between mica surfaces immersed in dextran solution
}

Emile Perez, J.E. Proust

\section{- To cite this version:}

Emile Perez, J.E. Proust. Effects of a non-adsorbing polymer on colloid stability : force measurements between mica surfaces immersed in dextran solution. Journal de Physique Lettres, 1985, 46 (2), pp.79-84. 10.1051/jphyslet:0198500460207900 . jpa-00232481

HAL Id: jpa-00232481

https://hal.science/jpa-00232481

Submitted on 1 Jan 1985

HAL is a multi-disciplinary open access archive for the deposit and dissemination of scientific research documents, whether they are published or not. The documents may come from teaching and research institutions in France or abroad, or from public or private research centers.
L'archive ouverte pluridisciplinaire HAL, est destinée au dépôt et à la diffusion de documents scientifiques de niveau recherche, publiés ou non, émanant des établissements d'enseignement et de recherche français ou étrangers, des laboratoires publics ou privés. 
Classification

Physics Abstracts

$68.15-68.45-82.70-82.65$

\title{
Effects of a non-adsorbing polymer on colloid stability : force measurements between mica surfaces immersed in dextran solution
}

\author{
E. Perez and J. E. Proust \\ Physico-Chimie des Surfaces et des Membranes $\left(^{*}\right)$, UER Biomédicale, 45 rue des Saints-Pères, \\ 75270 Paris Cedex 06, France
}

(Reçu le 22 juin 1984, révisé le 15 octobre, accepté le 21 novembre 1984)

\begin{abstract}
Résumé. - Les forces de surface ont été mesurées entre deux feuilles de mica en configuration de cylindres croisés en présence de chlorure de sodium. Pour différentes concentrations de $\mathrm{NaCl}\left(1^{-4}\right.$, $10^{-3}, 10^{-2} \mathrm{M}$ ), on observe, aux faibles distances, une contribution additionnelle attractive aux forces DLVO quand le dextrane est ajouté à la solution aqueuse. La conséquence la plus frappante de cet effet est que le saut en contact des feuilles de mica survient à des distances plus grandes et pour des forces de compression plus faibles qu'avec l'électrolyte pur; de plus, même dans des cas où les forces d'hydratation empêchent ce saut en contact $\left(\mathrm{NaCl} 10^{-2} \mathrm{M}\right)$, l'addition de dextrane le permet. Dans tous les cas ce contact se fait à distance nulle, ce qui prouve qu'il n'y a pas de dextrane adsorbé irréversiblement aux surfaces. Ces résultats expérimentaux sont analysés en rapport avec les théories récentes concernant l'effet de la déplétion des polymères sur la stabilité des colloïdes.
\end{abstract}

\begin{abstract}
The forces between two cylindrically curved mica surfaces have been measured in aqueous dextran solution in the presence of $\mathrm{NaCl}$. At various $\mathrm{NaCl}$ concentrations $\left(10^{-4}, 10^{-3}\right.$, $10^{-2} \mathrm{M}$ ) we observe an additional attractive contribution to DLVO forces when dextran is added to the aqueous solution. The most striking consequence of this effect is that the jumps into primary minimum contact occur at larger distances and at weaker forces than with pure electrolyte solution; moreover in some cases where hydration forces prevent the jump in primary minimum contact $\left(\mathrm{NaCl} 10^{-2} \mathrm{M}\right)$, the addition of dextran produces this jump. In all cases the primary minimum contact takes place at zero distance which proves that no adsorbed dextran is trapped between the two mica surfaces. These experimental results are analysed and compared with the recent theories of polymer depletion effect on colloid stability.
\end{abstract}

\section{Introduction.}

Amongst the many problems related to colloid stability, the aggregative properties of soils have great practical importance. Organic polymers are well known to aggregate and bridge soil mineral particles [1, 2]. Pagliai et al. [3] have shown that the stability of soils depends on the concentration and molecular weight of dextrans. Much work has been done both theoretically [4-8] and experimentally $[9,10]$ on the stabilization of colloidal systems by polymers. Two situa-

(*) Equipe de Recherche du CNRS associée à l'Université Paris V. 
tions are distinguished depending on whether the polymer adsorbs on the particles or not. In both cases, a colloidal system may be stabilized or destabilized. Four behaviours may be encountered : adsorption stabilization or adsorption flocculation, and depletion stabilization or depletion flocculation. While the adsorbing case has been thoroughly investigated, the nonadsorbing case has mainly been studied from a theoretical point of view. Joanny et al. [5] have predicted that when the polymer does not adsorb, there is a decrease in polymer concentration near one wall (depletion layer) leading to an attractive contribution between two such walls. Scheutjens and Fleer [6] have computed the interaction between two walls across polymer solution in the four cases cited above. Usual techniques for measuring adsorption are inadequate for detecting depletion. Only one technique (Evanescent Wave Induced Fluorescence, EWIF) has been successfully applied to give direct information on the depletion layer [11]. However no measurements of corresponding surface forces have been reported.

In this paper, we report on the effect of the presence of dextran (a neutral polymer) on the forces between two mica surfaces immersed in aqueous $\mathrm{NaCl}$ solution. Dextran is an almost perfect statistical compact coil for molecular weights above $2000[12,13]$. Muscovite mica cleavage plane is generally admitted as a good model for clays in general and illite in particular.

\section{Experimental.}

2.1 Materials. - The water used was tridistilled, the second distillation being made from acid potassium permanganate and had very low babble persistence. The $\mathrm{pH}$ value of the water was typically 5.6. The $\mathrm{NaCl}$ was obtained from Merck Suprapur $99.5 \%$, and roasted 6 hours at $600^{\circ} \mathrm{C}$. The concentrated $\mathrm{NaCl}$ solutions were filtrated through fluoropore $0.2 \mu \mathrm{m}$. Dextran, with molecular weight $M_{\mathrm{w}}=2 \times 10^{6}$, was obtained from Sigma (D5376) and used without further purification. The radius of gyration $R_{\mathrm{G}}$ of dextran can be calculated using the relation $R_{\mathrm{G}}=0.6 M^{0.43}$ determined by Snabre et al. [13] (these authors explain the exponent 0.43 by branching), for $M \simeq 2 \times 10^{6}, R_{\mathrm{G}} \simeq 31 \mathrm{~nm}$.

2.2 Methods AND PROCEDURE. - The force $F$ between two molecularly smooth curved (of radius $R=2 \mathrm{~cm}$ ) mica surfaces as a function of distance $D$ was measured using the method developed by Israelachvili and extensively described in reference [14]. The apparatus was thermostated at $20 \pm 0.1^{\circ} \mathrm{C}$. The separation $D$ between the surfaces was measured with an accuracy of $(0.1-0.2) \mathrm{nm}$. The value $F / R$ is plotted in the graphs as a function of $D$, and is equal to $2 \pi E$, where $E$ is the corresponding energy between flat surfaces [15]. The mica surfaces are first immersed in water and left for an hour. Then we check that on bringing the surfaces towards each other, they jump into contact from a repeatable distance of $\sim 2.5 \mathrm{~nm}$ which is a good test for the absence of organic or particulate contamination [16]. Water is then replaced by $\mathrm{NaCl}$ solution and after 2 hours, force/distance profiles are determined. Then dextran is added. The results reported are obtained from at least two independent experiments.

\section{Results.}

The reference distance $D=0$ is the one obtained when the mica surfaces are contacting in pure $\mathrm{NaCl}$ solution. When dextran was added at all used concentrations $(0.1$ to $0.6 \mathrm{~g} / \mathrm{l})$ and for incubation times up to 8 days, the mica surfaces always contacted at the same reference distance $D=0$ (measured within $\pm 0.15 \mathrm{~nm}$ accuracy). This result shows that no layer of dextran remains on the surfaces (no irreversible adsorption) when they are brought into contact. At all distances where refractive index was measured $(10$ to $100 \mathrm{~nm}$ ), it was found equal to that of the pure $\mathrm{NaCl}$ solution.

It has already been mentioned that in the presence of macromolecules, force/distance profiles may show a hysteresis. We have shown the importance of this phenomenon in a previous study of forces between mica surfaces bearing adsorbed mucin (BSM) [17]. Luckham and Klein [10] 
have extensively studied force/distance profiles in the presence of adsorbed polylysine in compression-decompression cycles. Each curve presented here has been obtained from a first conpression when the surfaces were brought from large distance $(800 \mathrm{~nm})$ to contact with a monotonic displacement (no receding, no use of piezoelectric tube, use of the differential spring system only [14]). All results obtained with pure $\mathrm{NaCl}$ solution are in agreement with those published by Pashley [18].

Figure 1a shows the force/distance profile in $\mathrm{NaCl} 10^{-4} \mathrm{M}$ and in $\mathrm{NaCl} 10^{-4} \mathrm{M}+$ dextran $0.3 \mathrm{~g} / \mathrm{l}$. In $\mathrm{NaCl} 10^{-4} \mathrm{M}$, the surfaces jump into primary minimum contact at $D=2.0 \pm 0.4 \mathrm{~nm}$. With dextran $0.3 \mathrm{~g} / \mathrm{l}$, this jump occurs at $D=5.5 \pm 0.4 \mathrm{~nm}$ and at a weaker force. Figure $1 \mathrm{~b}$ gives the difference between these two curves. An attractive contribution after dextran is added becomes noticeable from $30 \mathrm{~nm}$ distance. A weak repulsive contribution for $D>50 \mathrm{~nm}$ is also measured (Fig. 1a). At a lower concentration (dextran $0.1 \mathrm{~g} /$ ), only an attractive contribution is measured (results not shown).

The jump into primary minimum contact occurs at $D=1.8 \mathrm{~nm} \pm 0.4 \mathrm{~nm}$ in $\mathrm{NaCl} 10^{-3} \mathrm{M}$ and at $4.0 \pm 0.4 \mathrm{~nm}$ in $\mathrm{NaCl} 10^{-3} \mathrm{M}+$ dextran $0.1 \mathrm{~g} / 1$ (Fig. 2a). Figure $2 \mathrm{~b}$ shows the attractive contribution after the addition of dextran.
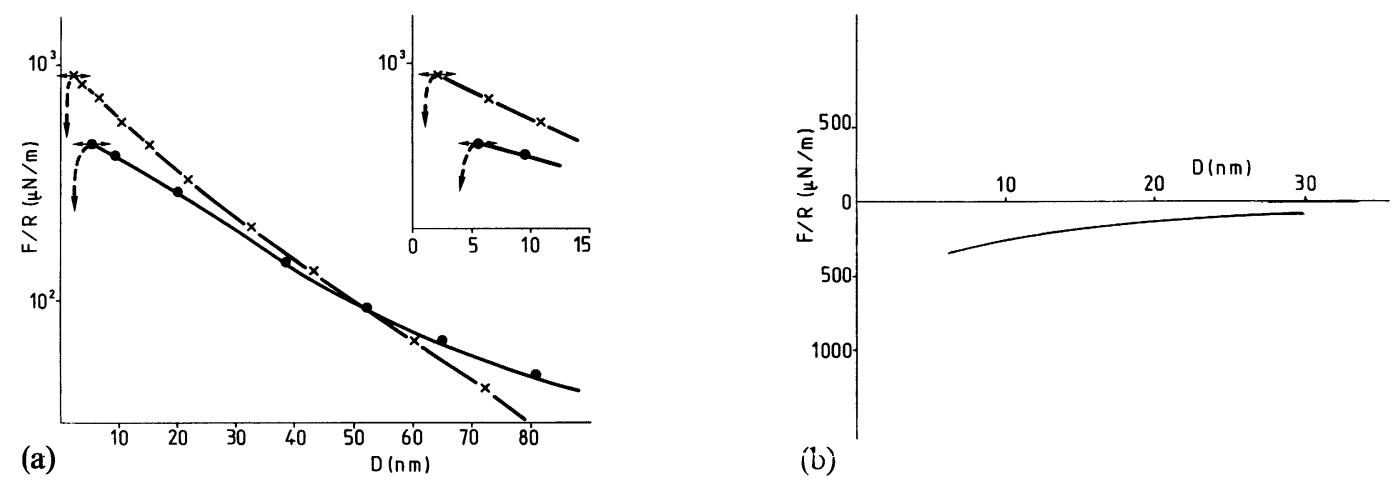

Fig. 1. - (a) Forces measured between mica surfaces in $\mathrm{NaCl} 10^{-+} \mathrm{M}(\times)$ and $\mathrm{NaCl} 10^{-4} \mathrm{M}+$ dextran $0.3 \mathrm{~g} / \mathrm{l}(\bullet)$. (b) Difference between the two curves.
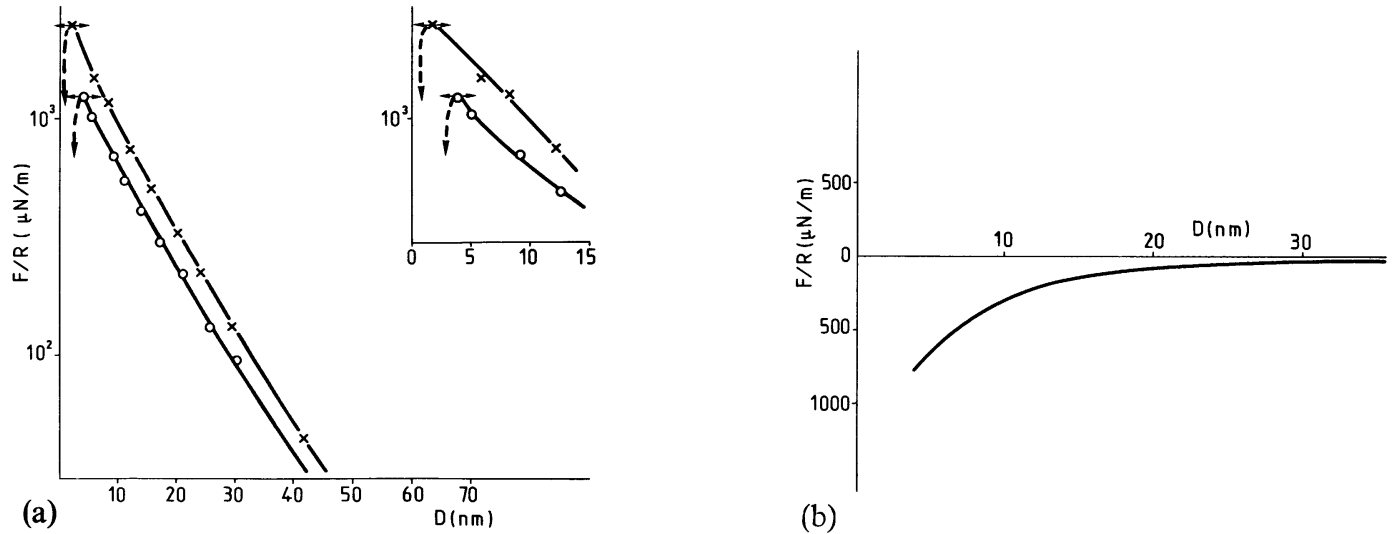

Fig. 2. - (a) Forces measured between mica surfaces in $\mathrm{NaCl} 10^{-3} \mathrm{M}(\times)$ and $\mathrm{NaCl} 10^{-3} \mathrm{M}+$ dextran $0.1 \mathrm{~g} / 1(\mathrm{O})$. (b) Difference between the two curves. 
In $\mathrm{NaCl} 10^{-2} \mathrm{M}$, hydration forces remove the primary minimum contact, as was observed by Pashley [18], and we have observed no jump into contact. With dextran $0.1 \mathrm{~g} / 1$, a jump into primary minimum contact occurs at $D=1.6 \pm 0.4 \mathrm{~nm}$ (Fig. 3a). Figure $3 \mathrm{~b}$ shows the attractive contribution in the presence of dextran. When the dextran concentration is increased to $0.3 \mathrm{~g} / \mathrm{l}$, the jump into contact occurs at a weaker force and from almost the same distance. In this case there is a repulsive contribution at distances greater than $10 \mathrm{~nm}$.

\section{Discussion.}

These first results obtained with a commercial dextran will be discussed in this paper mainly from a qualitative point of view. The adsorption of dextran on clays is still controversial [19, 20]. Adsorption on various types of clays of the same dextran we used was recently found to be two orders of magnitude lower than of other polysaccharides [21]. We have found that no irreversible adsorption of this dextran occurs on mica. Two possibilities then remain : reversible adsorption or depletion. De Gennes [7] has proved that for flexible polymer chains, the interaction between plates is always attractive when the chains can exchange reversibly with a bulk solution. As the repulsive regime is observed within a certain concentration and distance range, it seems that the depletion of dextran molecules at the solution/mica interface takes place. Measurements of the concentration profiles for the same system with the EWIF technique, for instance, would be determinant.

In qualitative agreement with Asakura et al. [4] and Joanny et al. [5], an attractive regime is observed in every case. This effect is noticeable at distances up to $30-40 \mathrm{~nm}$ and may be determinant in many cases. Increasing dextran concentration reduces the distance at which attraction is detectable (Fig. 3b), in agreement with Ausseré et al. [11] who measured depletion profiles with Xanthan with the same molecular weight and concentrations. Moreover, a repulsive contribution is obtained at larger distances (Fig. 3b) in agreement with Scheutjens and Fleer [6]. The effect of increasing dextran concentration at fixed ionic strength is to reduce the height of the force barrier (Fig. 3a).
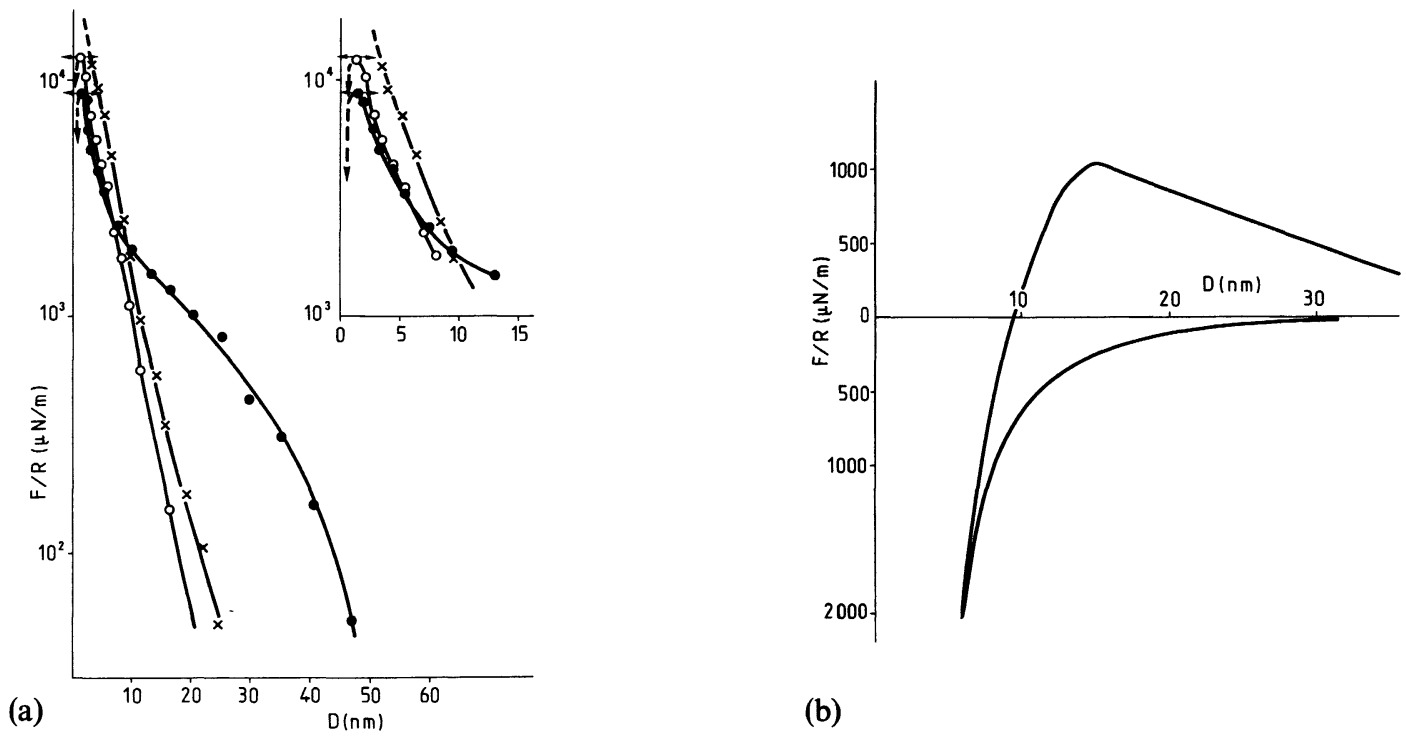

Fig. 3. - (a) Forces measured between surfaces in $\mathrm{NaCl} 10^{-2} \mathrm{M}(x) ; \mathrm{NaCl}_{10}^{-2} \mathrm{M}+$ dextran $0.1 \mathrm{~g} / 1(\mathrm{O})$ and $\mathrm{NaCl} 10^{-2} \mathrm{M}+$ dextran $0.3 \mathrm{~g} / 1(\bullet)$. (b) Difference between $\mathrm{NaCl} 10^{-2} \mathrm{M}$ reference curve and curves obtained with dextran. 
Increase of $\mathrm{NaCl}$ concentration increases the attractive contribution (Fig. 1b and Fig. 3b). As far as a quantitative comparison with the theory of depletion effects is concerned, a simple evaluation of depletion attraction from osmotic pressure, calculations [4] in the dilute case $\left(c<c^{*}=M_{\mathrm{W}} /\left(4 / 3 \pi R_{\mathrm{G}}^{3}\right) \simeq 30 \mathrm{~g} / 1\right.$ with $R_{\mathrm{G}} \simeq 31 \mathrm{~nm}, c^{*}$ is the first overlap concentration $)$ gives a value of $E \simeq F / 2 \pi R \simeq 10^{-2} \mu \mathrm{J} / \mathrm{m}^{2}$. The effect we observed is much higher than one may evaluate theoretically in a dilute system.

In the case of a semi-dilute system, the magnitude of the depletion attraction would be : $E \simeq F / 2 \pi R \simeq k T / \xi^{2}$, where $\xi$ is taken as the radius of gyration of the polymer (cf. Eq. (3.2) of Ref. [5]). We have $F / R \simeq 24 \mathrm{~J} / \mathrm{m}^{2}$, which is closer to the observed attractive contribution.

To investigate further this discrepancy, other possibilities may be considered. It must be pointed out that the surface forces measurement technique is very sensitive to the presence of impurities [22-25] and that any analysis of the results must include such a possibility. If there were ionic impurities, they would provoke a decrease of the decay-lengths of the forces, opposite to that shown in figure 1 (the lowest ionic strength). If there were hydrophobic impurities adsorbing on mica, they would produce an attractive contribution [16]. However, such impurities, if present, would have been noticed and would influence upon the contact which always occurred at the reference distance $D=0 \pm 0.15 \mathrm{~nm}$.

It is worth mentioning that, when the dextran- $\mathrm{NaCl}$ solution was replaced by a pure $\mathrm{NaCl}$ solution, the force-distance profiles were identical to the ones measured in $\mathrm{NaCl}$ prior to the addition of dextran.

Finally, we have performed measurements with high quality dextran [27] (molecular weight $\left.M_{\mathrm{w}}=1400000, M_{\mathrm{W}} / M_{\mathrm{N}}=1.965\right)$. The experimental results shown in figure 4 are qualitatively and quantitatively similar to the ones obtained with commercial dextran.

In any case, the observed phenomenon cannot be attributed to the sole dextran effect. Comparison of the figures $1 \mathrm{~b}, 2 \mathrm{~b}$ and $3 \mathrm{~b}$ makes it obvious that the attractive contribution is dramatically enhanced by $\mathrm{NaCl}$. In references [12] and [28] the salting-out effects for dextran and the increase of its radius of gyration with ionic strength are described. The effect of the salt on the attractive contribution remains unexplained at present.

\section{Conclusion.}

These results show that, in the non-adsorbing case, on top of the usual surface forces, an additional contribution is measured. This contribution depends on the polymer concentration and $\mathrm{NaCl}$ concentration. At large distances, repulsive interactions may be observed in some cases. At small
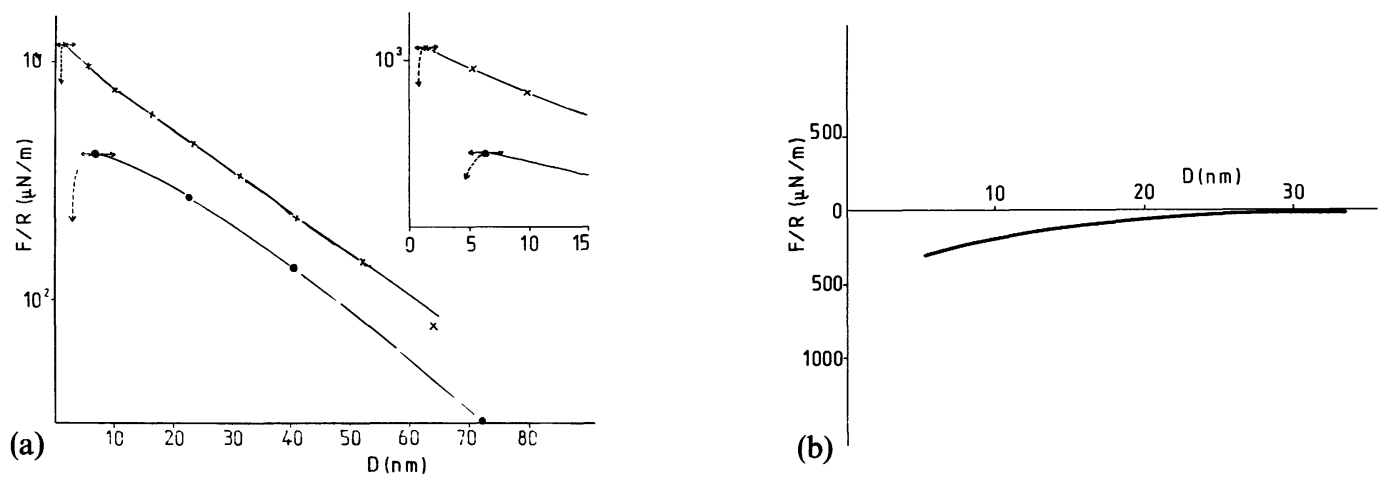

Fig. 4. - (a) Forces measured between surfaces in $\mathrm{NaCl} 10^{-4} \mathrm{M}(x) ; \mathrm{NaCl}_{10} 0^{-4} \mathrm{M}+$ dextran $0.15 \mathrm{~g} / 1(\mathrm{O})$. Here this dextran was non-commercial [27]. (b) Difference between $\mathrm{NaCl} 10^{-4} \mathrm{M}$ reference curve and curve obtained with dextran. 
distances, an attractive contribution is always obtained. This interaction is so important that it can produce a jump into primary minimum contact in cases when hydration forces prevent it in pure $\mathrm{NaCl}$ solution. These results seem to be related to depletion (non-adsorption) of dextran. They cannot, however, be entirely explained by the recent theories of depletion effects. This observed effect may be very important for the stability of colloids. Our study also shows that dextran, even at low concentrations in clay soils, may have a determinant influence on their properties.

\section{Acknowledgments.}

This work was supported in part by the grant " Matières Organiques dans les Sols » from the Ministère de l'Environnement (No 508001).

\section{References}

[1] Martin, J. P., Erwin, J. O. and Richards, S. J., J. Soil Sci. 113 (1972) 322.

[2] Quirk, J. P. and Williams, B. G., Trans. 10th Int. Cong. Soil Sci. Moscow 1 (1974) 165.

[3] Pagliai, M., Guidi, G. and Petruzzelli, G., in Modification of Soil Structure, Eds. W. W. Emerson, R. D. Bond and A. R. Dexter (Wiley Intersci. Publ.) 1978, p. 35.

[4] Asakura, S. and Oosawa, F., J. Chem. Phys. 22 (1954) 1255.

[5] Joanny, J. F., Leibler, L. and De Gennes, P. G., J. Polym. Sci. 17 (1979) 1073.

[6] Scheutjens, J. M. H. M. and Fleer, G. J., Adv. Colloid Interface Sci. 16 (1982) 361.

[7] De Gennes, P. G., Macromolecules 15 (1982) 492.

[8] Eisenriegler, E., J. Chem. Phys. 79 (1983) 1052.

[9] Klein, J., J. Chem. Soc. Faraday Trans. 179 (1983) 99.

[10] Luckham, P. and Klein, J., J. Chem. Soc. Faraday Trans. 180 (1984) 865.

[11] Ausseré, D., Hervet, H. and Rondelez, F., Colloque Interactions solide-liquide dans les milieux poreux, Feb. 1984, Nancy (France).

[12a] Basedow, A. M. and Ebert, K. H., J. Polym. Sci., Polym. Symp. 66 (1979) 101.

[12b] Basedow, A. M., Ebert, K. H. and Feigenbutz, W., Makromol. Chem. 181 (1980) 1071.

[13] Snabre, P., Grossman, . and Mills, P., J. Colloid Polym. Sci. (submitted).

[14] Israelachvili, J. N. and Adams, G. E., J. Chem. Soc. Faraday Trans. 174 (1978) 975.

[15] Derjaguin, B. V., Kolloid-Z. 69 (1934) 155.

[16] HoRN, R. G., private communication.

[17] Perez, E. and Proust, J. E., Colloque Colloides et Interfaces, Paris, Nov. 1982 ;

Perez, E., Proust, J. E. and Baszkin, A., Colloque Physico-chimie des Colloides et Interfaces : Biotechnologies et Médicaments Paris, sept. 1983 ;

Proust, J. E., Baszkin, A., Perez, E. and Boissonnade, M. M., Colloids and Surfaces, in press.

[18] Pashley, R. M., J. Colloid Interface Sci. 83 (1981) 531.

[19] Clapp, C. E. and Emerson, W. W., Soil Sci. 114 (1972) 210.

[20] Parfitt, R. L. and Greenland, D. J., Soil. Sci. Soc. Amer. Proc. 34 (1970) 862.

[21] CHENU, C., private communication.

[22] Israelachvili, J. N., Pashley, R. M., Perez, E. and Tandon, R. K., Colloids Surfaces 2 (1981) 287.

[23] Christenson, H. K., Horn, R. G. and Israelachvili, J. N., J. Colloid Interface Sci. 88 (1982) 79.

[24] Israelachvili, J. N., TANDON, R. K. and White, L. R., J. Colloid Interface Sci. 78 (1980) 432.

[25] Klein, J., Nature 300 (1982) 429.

[26] Israelachvili, J. N. and Pashley, R. M., J. Colloid Interface Sci. 98 (1984) 500.

[27] This dextran was prepared at the «Institut für Angewandte Physikalische Chemie der Universität Heidelberg " [11] and was kindly provided to us by P. Snabre.

[28] Antonini, E., Bellelli, M., Bruzzezi, M., Chiancone, E. and Rossi-Fanelli, A., Biopolymers 2 (1964) 27. 